Article

\title{
Robust Finite-Time Tracking Control for Robotic Manipulators with Time Delay Estimation
}

\author{
Tie Zhang $($ and Aimin Zhang * (D) \\ School of Mechanical \& Automotive Engineering, South China University of Technology, \\ Guangzhou 510640, China; merobot@scut.edu.cn \\ * Correspondence: gdzham@yeah.net
}

Received: 4 December 2019; Accepted: 21 January 2020; Published: 28 January 2020

check for updates

\begin{abstract}
In this study, a robust $\mathrm{H}_{\infty}$ finite-time tracking controller is proposed for robotic manipulators based on time delay estimation. In this controller, there is no need to know the dynamics of robots, so it is quite simple. The high-gain observer is employed to estimate the joint velocities, which makes it much lower in cost. The theorem proof shows that the closed-loop system is finite-time stable and has a $L_{2}$ gain that is less than or equal to $\gamma$, which shows high accuracy and strong robustness to estimation errors and external disturbances. Simulations on a two-link robot illustrate the effectiveness and advantages of the proposed controllers.
\end{abstract}

Keywords: finite-time control; time delay estimation; robust $\mathrm{H}_{\infty}$; robotic manipulators; high-gain observer

\section{Introduction}

The control performances of robotic manipulators are becoming more and more important in industrial fields, especially fast response, high precision, and strong robustness. However, it is quite difficult to obtain the satisfied performances due to highly coupled nonlinear dynamics, time-varying behavior and unknown uncertainties, such as model uncertainties and external disturbances. Fortunately, there are many good results about controllers for robotic manipulators, such as adaptive control [1], robust control [2], and sliding mode control [3]. One of the powerful existing controller is the finite-time control [4] that presents finite-time convergence, which provides fast response and high precision. Thus far, there are many finite-time control methods, such as the finite-time stabilization approach for homogeneous systems [5,6], finite-time Lyapunov stabilization approach [7-10], terminal sliding mode approach [11-17], and super-twisting algorithm [18,19]. In particular, Ali Abooee et al. proposed a chattering-free second order fast nonsingular terminal sliding mode controller for robotic manipulators with unknown disturbances [15]. Yassine Kali and Maarouf Sadd proposed a high-accuracy trajectory tracking controller for robotic manipulators with uncertainties and unexpected disturbances based on the super-twisting algorithm [19], but it only ensured that the selected linear sliding surface converged to zero in a finite time. Su and Zheng proposed a finite-time tracking controller for robotic manipulators by using nonlinear exponential-like errors and inverse dynamics control [20]. Mirosław Galicki proposed an absolutely continuous terminal sliding mode controller for robotic manipulators based on first and second-order sliding mode control techniques [21]. In these results, the super-twisting algorithm and terminal sliding mode control scheme presented stronger robustness to uncertainties, but in the process of the control design, there was no discussion about the relationship between robustness and the control parameters. Recently, Liu and Zhang [22] discussed this relationship and proposed a finite-time $H_{\infty}$ controller for uncertain robotic manipulators. However, the controller is also complex due to the requirements of the dynamics mode, especially for more than four-degrees of freedom in robotic manipulators. For this reason, the time delay estimation 
is used to simplify the controller design [18,19]; however, the work in References [18,19] only guarantee that the closed-loop system is asymptotically convergent.

Motivated by the above works, this work will propose a robust finite-time output feedback controller for uncertain manipulators as follows: (1) The time delay estimation is used to estimate the robot dynamics and to simplify the controller structure, which is simpler to implement in practice; (2) the closed-loop system is not only finite-time stable, but also has the $L_{2}$ gain less than or equal to $\gamma$, so there is no need to solve the complex Hamilton-Jacobi equation or the Riccati equation; and (3) the high-gain observer is employed to estimate joint velocities, which in practice makes lower in cost.

The rest of paper is organized as follows. Section 2 shows preliminaries, such as the robot dynamic model and the relative finite-time stability theorems. Section 3 presents the main results from the controller design. Section 4 gives the simulations on a two-link robot. Finally, Section 5 provides some conclusions.

\section{Preliminaries}

\subsection{Relative Theorems}

The following finite-time $\mathrm{H}_{\infty}$ control theorem can be used.

Lemma 1 [22]. Consider the nonlinear system $\dot{x}=f(x, u), z=h(x)$. Suppose that there is a $C^{1}$ function $V(x)$ defined in a neighborhood $\hat{U} \subset R^{n}$ of the origin and real numbers $c>0$ and $0<\alpha<1$, such that

(i) $V(x)$ is positive definite in $\hat{U}$;

(ii) $\dot{V}(x)+c V^{\alpha}(x) \leq \frac{1}{2}\left(\gamma^{2}\|w\|^{2}-\|z\|^{2}\right), \forall x \in \hat{U} \backslash\{0\}$.

Then, the origin of the system $\dot{x}=f(x, u)$ is locally finite-time stable and the system has a $L_{2}$ gain less than or equal to $\gamma$. If $\hat{U}=R^{n}$ and $V(x)$ is radially unbounded (i.e., $V(x) \rightarrow+\infty$ as $\|x\| \rightarrow+\infty$ ), then the origin of the system (1) is also globally finite-time stable.

Obviously, it is important and difficult to design a robust controller $u$ and find a satisfied Lyapunov function $V(x)$.

\subsection{Problem Formulation}

The $n$-DOF robotic manipulator dynamic [23] is given in the form of

$$
M(q) \ddot{q}+C(q, \dot{q}) \dot{q}+G(q)=\tau+\tau_{d}
$$

where $q, \dot{q}, \ddot{q} \in R^{n}$ are the joint position, velocity and acceleration vectors, respectively. $M(q) \in R^{n \times n}$ is the inertia matrix, $C(q, \dot{q}) \in R^{n \times n}$ is the centrifugal and Coriolis matrix, $G(q) \in R^{n}$ is the gravitational vector, and $\tau_{d}, \tau \in R^{n}$ denotes the disturbance and torque input vectors, respectively.

In practice, it is difficult to exactly know the inertia matrix $M(q)$, especially for more than 4 degrees of freedom of robotic manipulators. In order to simplify the controller, a constant matrix is introduced to constitute the inertia matrix, so the dynamic equation of the robotic manipulator is expressed as

$$
\bar{M} \ddot{q}+H(q, \dot{q}, \ddot{q})=\tau
$$

where

$$
H(q, \dot{q}, \ddot{q})=[M(q)-\bar{M}] \ddot{q}+C(q, \dot{q}) \dot{q}+G(q)-\tau_{d}
$$

Define the desired trajectory $q_{d} \in R^{n}$, and $e=q-q_{d}$ is defined as the tracking error. The main objective of this paper is to design a robust controller $\tau$ so that the tracking error $e$ can convergence to zero in a finite time, even in the presence of uncertainties and external disturbances, and the $L_{2}$ gain of the system is less than or equal to given $\gamma$, i.e., $e \rightarrow 0$ when $t \rightarrow T$. 


\section{Main Results}

Define $x_{1}=q-q_{d} \in R^{n}, x_{2}=\dot{q}-\dot{q}_{d}=\dot{x}_{1} \in R^{n}$, the (2) can be rewritten as

$$
\left\{\begin{array}{l}
\dot{x}_{1}=x_{2} \\
\dot{x}_{2}=\bar{M}^{-1} \tau-\ddot{q}_{d}+w
\end{array}\right.
$$

where $w(t)=-\bar{M}^{-1} H(q, \dot{q}, \ddot{q})$ can be seen as uncertainties. In practice, the $w(t)$ is impossible to know, but $w(t)$ can be estimated using a time delay estimation (TDE) [24] as:

$$
\hat{w}(t) \approx w(t-L)=\dot{x}_{2}(t-L)-M^{-1} \tau(t-L)
$$

Design a following controller

$$
\tau=\bar{M}\left(v+\ddot{q}_{d}-\hat{w}\right)
$$

where $v$ will be designed in the following.

Combine Equations (4) and (6), we can obtain

$$
\left\{\begin{array}{l}
\dot{x}_{1}=x_{2} \\
\dot{x}_{2}=v+\widetilde{w}
\end{array}\right.
$$

where $\widetilde{w}=w-\hat{w}$ is the TDE error, and $\widetilde{w}$ is bounded, the proof will be in Appendix A.

In order to improve the robustness to uncertainties, the $L_{2}$ gain will be set as $\gamma, \gamma>0$.

Define auxiliary vector $\rho_{1}\left(x_{1}\right) \in R^{n}$ with $\rho_{1}(0)=0$, and

$$
\eta_{1}=x_{2}-\rho_{1}\left(x_{1}\right)
$$

If we design the following functions:

$$
\begin{aligned}
& \rho_{1}\left(x_{1}\right)=-L_{0} x_{1}-L_{1} \operatorname{Sig}^{\xi}\left(x_{1}\right) \\
& \rho_{2}\left(\eta_{1}\right)=-L_{2} \operatorname{Sig} \xi\left(\eta_{1}\right)
\end{aligned}
$$

where $L_{0}=\operatorname{diag}\left(l_{01}, l_{02}, \ldots, l_{0 \mathrm{n}}\right), L_{1}=\operatorname{diag}\left(l_{11}, l_{12}, \ldots, l_{1 \mathrm{n}}\right), L_{2}=\operatorname{diag}\left(l_{21}, l_{22}, \ldots, l_{2 \mathrm{n}}\right)$, all the elements are positive, and $0<\xi<1$.

Then, select the following evaluation signal of performance:

$$
z=\left[\begin{array}{l}
\lambda_{1} x_{1} \\
\lambda_{2} \eta_{1}
\end{array}\right]
$$

where $\lambda_{1}>0$, and $\lambda_{2}>0$ are defined as weighted coefficients.

In order to obtain a robust $H_{\infty}$ finite-time control law, the $v$ is designed as

$$
v=\rho_{2}\left(\eta_{1}\right)-x_{1}-\left(\frac{1}{2 \gamma^{2}}+\frac{\lambda_{2}^{2}}{2}\right) \eta_{1}+\dot{\rho}_{1}\left(x_{1}\right)
$$

where $l_{0}=\min \left\{l_{0 i}\right\}, i=1, \ldots, n, l_{0} \geq \lambda_{1}{ }^{2} / 2, \gamma>0$. Then, the closed-loop system is globally finite-time stable and has a $L_{2}$-gain less than or equal to $\gamma$.

So we have the following theorem.

Theorem 1. For the robotic manipulators (4), if we design the controller as

$$
\tau=\bar{M}\left[\ddot{q}_{d}+\rho_{2}\left(\eta_{1}\right)-x_{1}-\left(\frac{1}{2 \gamma^{2}}+\frac{\lambda_{2}^{2}}{2}\right) \eta_{1}+\dot{\rho}_{1}\left(x_{1}\right)-\hat{w}\right]
$$


Then, the trajectory tracking error can converge to zero in a finite time, and the closed-loop system has $L_{2}$-gain less than or equal to $\gamma$.

Poof. According to Equations (7) and (11), we can obtain the following closed-loop system:

$$
\left\{\begin{array}{l}
\dot{x}_{1}=\eta_{1}+\rho_{1}\left(x_{1}\right) \\
\dot{\eta}_{1}=\rho_{2}\left(\eta_{1}\right)+\widetilde{w}(x)-x_{1}-\left(\frac{1}{2 \gamma^{2}}+\frac{\lambda_{2}^{2}}{2}\right) \eta_{1}
\end{array}\right.
$$

So we select the following Lyapunov function

$$
V=\frac{1}{2} x_{1}^{T} x_{1}+\frac{1}{2} \eta_{1}^{T} \eta_{1}
$$

and differentiate it with time, and combine it with Equations (13) and (19), and we can obtain

$$
\begin{aligned}
\dot{V} & =x_{1}^{T} \dot{x}_{1}+\eta_{1}^{T} \dot{\eta}_{1} \\
& =x_{1}^{T}\left(\eta_{1}+\rho_{1}\left(x_{1}\right)\right)+\eta_{1}^{T}\left(\rho_{2}\left(\eta_{1}\right)+\widetilde{w}(x)-x_{1}-\left(\frac{1}{2 \gamma^{2}}+\frac{\lambda_{2}^{2}}{2}\right) \eta_{1}\right) \\
& =x_{1}^{T} \rho_{1}\left(x_{1}\right)+\eta_{1}^{T} \rho_{2}\left(\eta_{1}\right)+\eta_{1}^{T} \widetilde{w}(x)-\left(\frac{1}{2 \gamma^{2}}+\frac{\lambda_{2}^{2}}{2}\right) \eta_{1}^{T} \eta_{1} \\
& =-x_{1}^{T} L_{1} \operatorname{Sig}^{\xi}\left(x_{1}\right)-\eta_{1}^{T} L_{2} \operatorname{Sig}^{\xi}\left(\eta_{1}\right)-x_{1}^{T} L_{0} x_{1}+\eta_{1}^{T} \widetilde{w}(x)-\left(\frac{1}{2 \gamma^{2}}+\frac{\lambda_{2}^{2}}{2}\right) \eta_{1}^{T} \eta_{1}
\end{aligned}
$$

Define the following function

$$
\Gamma=\dot{V}+\frac{1}{2}\left(\|z\|^{2}-\gamma^{2}\|\widetilde{w}\|^{2}\right)
$$

and combine it with Equations (10) and (15), and we can get

$$
\begin{aligned}
\Gamma= & \dot{V}+\frac{1}{2}\left(\|z\|^{2}-\gamma^{2}\|\widetilde{w}\|^{2}\right) \\
= & -x_{1}^{T} L_{1} \operatorname{Sig}^{\xi}\left(x_{1}\right)-\eta_{1}^{T} L_{2} \operatorname{Sig}^{\xi}\left(\eta_{1}\right)-x_{1}^{T} L_{0} x_{1}+\eta_{1}^{T} \widetilde{w}(x)-\left(\frac{1}{2 \gamma^{2}}+\frac{\lambda_{2}^{2}}{2}\right) \eta_{1}^{T} \eta_{1} \\
& +\frac{1}{2}\left(\|z\|^{2}-\gamma^{2}\|\widetilde{w}\|^{2}\right) \\
= & -x_{1}^{T} L_{1} \operatorname{Sig}^{\xi}\left(x_{1}\right)-\eta_{1}^{T} L_{2} \operatorname{Sig}^{\xi}\left(\eta_{1}\right)-x_{1}^{T} L_{0} x_{1}+\eta_{1}^{T} \widetilde{w}(x)-\left(\frac{1}{2 \gamma^{2}}+\frac{\lambda_{2}^{2}}{2}\right) \eta_{1}^{T} \eta_{1} \\
& +\frac{1}{2}\left(\lambda_{1}^{2}\left\|x_{1}\right\|^{2}+\lambda_{2}^{2}\left\|\eta_{1}\right\|^{2}-\gamma^{2}\|\widetilde{w}\|^{2}\right) \\
= & -x_{1}^{T} L_{1} \operatorname{Sig}^{\xi}\left(x_{1}\right)-\eta_{1}^{T} L_{2} \operatorname{Sig}^{\xi}\left(\eta_{1}\right)-x_{1}^{T} L_{0} x_{1}+\eta_{1}^{T} \widetilde{w}(x)-\eta_{1}^{T} \frac{1}{2 \gamma^{2}} \eta_{1}+\frac{1}{2} \lambda_{1}^{2}\left\|x_{1}\right\|^{2}-\frac{1}{2} \gamma^{2}\|\widetilde{w}\|^{2} \\
\leq & -x_{1}^{T} L_{1} \operatorname{Sig}^{\xi}\left(x_{1}\right)-\eta_{1}^{T} L_{2} \operatorname{Sig}^{\xi}\left(\eta_{1}\right)-x_{1}^{T} L_{0} x_{1}+\left\|\eta_{1}\right\|\|\widetilde{w}\|-\eta_{1}^{T} \frac{1}{2 \gamma^{2}} \eta_{1}+\frac{1}{2} \lambda_{1}^{2}\left\|x_{1}\right\|^{2}-\frac{1}{2} \gamma^{2}\|\widetilde{w}\|^{2} \\
= & -x_{1}^{T} L_{1} \operatorname{Sig}^{\xi}\left(x_{1}\right)-\eta_{1}^{T} L_{2} \operatorname{Sig}^{\xi}\left(\eta_{1}\right)-x_{1}^{T} L_{0} x_{1}+\frac{1}{2} \lambda_{1}^{2}\left\|x_{1}\right\|^{2}-\left(\frac{1}{\sqrt{2} \gamma} \eta_{1}-\frac{\gamma}{\sqrt{2}} \widetilde{w}\right)^{T}\left(\frac{1}{\sqrt{2} \gamma} \eta_{1}-\frac{\gamma}{\sqrt{2}} \widetilde{w}\right) \\
\leq & -x_{1}^{T} L_{1} \operatorname{Sig}^{\xi}\left(x_{1}\right)-\eta_{1}^{T} L_{2} \operatorname{Sig}^{\xi}\left(\eta_{1}\right)-x_{1}^{T} L_{0} x_{1}+\frac{1}{2} \lambda_{1}^{2}\left\|x_{1}\right\|^{2} \\
\leq & -x_{1}^{T} L_{1} \operatorname{Sig}^{\xi}\left(x_{1}\right)-\eta_{1}^{T} L_{2} \operatorname{Sig}^{\xi}\left(\eta_{1}\right)-\left(l_{0}-\frac{1}{2} \lambda_{1}^{2}\right)\left\|x_{1}\right\|^{2} \\
\leq & -x_{1}^{T} L_{1} \operatorname{Sig}^{\xi}\left(x_{1}\right)-\eta_{1}^{T} L_{2} \operatorname{Sig}^{\xi}\left(\eta_{1}\right)
\end{aligned}
$$


Let $\alpha=(1+\xi) / 2,1 / 2<\alpha<1, l_{1 \min }=\min \left\{l_{1 i}\right\}, l_{2 \min }=\min \left\{l_{2 i}\right\}, \widetilde{l_{1}}=2^{\alpha} l_{1 \min }, \widetilde{l}_{2}=2^{\alpha} l_{2 \min }$, and $\widetilde{l}=\min \left\{\widetilde{l}_{1}, \widetilde{l}_{2}\right\}$, and we can obtain

$$
\begin{aligned}
\Gamma & \leq-x_{1}^{T} L_{1} \operatorname{Sig}^{\xi}\left(x_{1}\right)-\eta_{1}^{T} L_{2} \operatorname{Sig}^{\xi}\left(\eta_{1}\right) \\
& \leq-l_{1 \min } \sum_{i=1}^{n}\left|x_{1 i}\right|^{1+\xi}-l_{2 \min } \sum_{i=1}^{n}\left|\eta_{1 i}\right|^{1+\xi} \\
& \leq-l_{1 \min }\left(\sum_{i=1}^{n} x_{1 i}^{2}\right)^{(1+\xi) / 2}-l_{2 \min }\left(\sum_{i=1}^{n} \eta_{1 i}^{2}\right)^{(1+\xi) / 2} \\
& \leq-\widetilde{l}_{1}\left(\frac{1}{2} \sum_{i=1}^{n} x_{1 i}^{2}\right)^{\alpha}-\widetilde{l}_{2}\left(\frac{1}{2} \sum_{i=1}^{n} \eta_{1 i}^{2}\right)^{\alpha} \\
& \leq-\widetilde{l} V^{\alpha}
\end{aligned}
$$

Therefore, the following inequality can be established:

$$
\dot{V}+\widetilde{l} V^{\alpha} \leq \frac{1}{2}\left(\gamma^{2}\|\widetilde{w}\|^{2}-\|z\|^{2}\right)
$$

Obviously, according to Lemma 1 , the system is finite-time stable and $L_{2}$ gain is less than or equal to $\gamma$. The proof is complete.

Remark 1. The robustness of controller can be adjusted by control parameters, so the TDE error cannot affect the tracking accuracy.

Remark 2. In order to avoid singularity, the derivative of $\operatorname{Sig}^{\xi}\left(x_{1}\right)$ should be modified by the function proposed in Reference [22] as follows:

$$
\left[\operatorname{Sig}^{\xi}\left(x_{1 i}\right)\right]^{\prime}=\left\{\begin{array}{cl}
\xi\left|x_{1 i}\right|^{\xi-1} \dot{x}_{1 i}, & \text { if }\left|x_{1 i}\right| \geq \varsigma \text { and } \dot{x}_{1 i} \neq 0 \\
\xi\left|\Delta_{1 i}\right|^{\xi-1} \dot{x}_{1 i}, & \text { if }\left|x_{1 i}\right|<\varsigma \text { and } \dot{x}_{1 i} \neq 0 \\
0, & \text { if } \dot{x}_{1 i}=0
\end{array}\right.
$$

where $\varsigma$ and $\Delta_{1 i}$ are both small positive constants, $x_{1 i}$ is the $i$ th element of the vector $x_{1}$.

Remark 3. In controller (12), the joint velocities need to be known, but the usage of speed sensors will increase the device cost. Thus, in this study, the joint velocities will be estimated by observers, such as high-gain observers and second-order sliding mode observers.

The high-gain observer is designed as

$$
\left\{\begin{array}{l}
\dot{\hat{x}}_{1}=\hat{x}_{2}+\frac{h_{1}}{\varepsilon}\left(x_{1}-\hat{x}_{1}\right) \\
\dot{\hat{x}}_{2}=\bar{M}^{-1} \hat{\tau}-\ddot{q}_{d}+\hat{w}+\frac{h_{2}}{\varepsilon^{2}}\left(x_{1}-\hat{x}_{1}\right)
\end{array}\right.
$$

where $h_{1}>0, h_{2}>0$, when the matrix

$$
\left[\begin{array}{ll}
-h_{1} & 1 \\
-h_{2} & 0
\end{array}\right]
$$

is Hurwitz [25], and the asymptotic error is convergent. Then, the observer-based controller is rewritten as

$$
\hat{\tau}=\bar{M}\left[\ddot{q}_{d}+\rho_{2}\left(\hat{\eta}_{1}\right)-x_{1}-\left(\frac{1}{2 \gamma^{2}}+\frac{\lambda_{2}^{2}}{2}\right) \hat{\eta}_{1}+\dot{\rho}_{1}\left(x_{1}\right)-\hat{w}\right]
$$

where $\hat{\eta}_{1}=\hat{x}_{2}-\rho_{1}\left(x_{1}\right)$.

Then, we have the following theorem. 
Theorem 2. For the robotic manipulators (4), if we design the observer as (21), and the controller as (22), Then, the trajectory tracking error can converge to zero in a finite time, and the closed-loop system has $L_{2}$-gain less than or equal to $\gamma$.

Proof. The separation principle can be used to prove the stability. So here is omitted.

Remark 4. The separation principle has significant practical implications because it allows the designer to design the state feedback controller to meet transient response specification and/or constraints on the state or control variables. Moreover, in the case of high-gain observers, it has a unique advantage that is to recover state trajectories by making observer sufficiently fast [25].

Remark 5. In practice, the performance of the high-gain observer system will be better than state feedback based on measurement in presence of noise, because in that case the observer acts as a low pass filter [26].

\section{Simulations}

In order to demonstrate the advantages of this study, a two-link robot is used in simulations. The two-link robot dynamic mode is

$$
\left[\begin{array}{ll}
m_{11} & m_{12} \\
m_{12} & m_{22}
\end{array}\right]\left[\begin{array}{l}
\ddot{q}_{1} \\
\ddot{q}_{2}
\end{array}\right]+\left[\begin{array}{cc}
-2 b \dot{q}_{2} & -b \dot{q}_{2} \\
b \dot{q}_{1} & 0
\end{array}\right]\left[\begin{array}{l}
\dot{q}_{1} \\
\dot{q}_{2}
\end{array}\right]=\left[\begin{array}{l}
\tau_{1} \\
\tau_{2}
\end{array}\right]+\tau_{d}
$$

where

$$
\begin{aligned}
& a_{11}=\left(m_{1}+m_{2}\right) r_{1}^{2}+m_{2} r_{2}^{2}+2 m_{2} r_{1} r_{2} \cos \left(q_{2}\right)+J_{1} \\
& a_{12}=m_{2} r_{1}^{2}+m_{2} r_{1} r_{2} \cos q_{2} \\
& a_{22}=m_{2} r_{2}^{2}+J_{2} \\
& b=m_{2} r_{1} r_{2} \sin q_{2}
\end{aligned}
$$

The parameters values are given in Table 1 . The external disturbance $\tau_{d}=0.5 \dot{q}^{2}+0.2 q+0.1$. The desired trajectory signals are $q_{\mathrm{d} 1}=\sin (2 \pi \mathrm{t}), q_{\mathrm{d} 2}=\sin (2 \pi \mathrm{t})$. The initial states are $q_{1}(0)=0.2 \mathrm{rad}, q_{2}(0)=$ $0.2 \mathrm{rad}, \dot{q}_{1}(0)=0 \mathrm{rad} / \mathrm{s}$, and $\dot{q}_{2}(0)=0 \mathrm{rad} / \mathrm{s}$.

Table 1. Dynamic parameter values.

\begin{tabular}{ccccccc}
\hline & $\boldsymbol{r}_{\mathbf{1}}(\mathbf{m})$ & $\boldsymbol{r}_{\mathbf{2}}(\mathbf{m})$ & $\left.\boldsymbol{J}_{\mathbf{1}} \mathbf{(} \mathbf{k g} \cdot \mathbf{m}^{\mathbf{2}}\right)$ & $\boldsymbol{J}_{\mathbf{2}}\left(\mathbf{k g} \cdot \mathbf{m}^{\mathbf{2}}\right)$ & $\boldsymbol{m}_{\mathbf{1}} \mathbf{( k g )}$ & $\boldsymbol{m}_{\mathbf{2}} \mathbf{( k g )}$ \\
\hline Actual values & 1 & 0.8 & 5 & 5 & 0.5 & 1.5 \\
Nominal values & 1.2 & 0.9 & 4.5 & 5.1 & 0.6 & 1.3 \\
\hline
\end{tabular}

There are two situations to illustrate the advantages by comparisons with the finite-time inverse tracking controller (FIDC) with state feedback proposed by Su and Zheng [20]. The FIDC is

$$
\tau=M_{0}(q)\left[\ddot{q}_{d}-k_{p} \operatorname{Sig}^{\beta_{1}}(e)-k_{d} \operatorname{Sig}^{\beta_{2}}(\dot{e})\right]+C_{0}(q, \dot{q}) \dot{q}+G_{0}(q)
$$

where $k_{p}=100, k_{d}=50, \beta_{1}=0.7$ and $\beta_{2}=2 \beta_{1} /\left(\beta_{1}+1\right)=0.82$.

(1) Robust finite-time state feedback control (FT-TDE)

The controller parameters are set as $\xi=0.8, L_{0}=\operatorname{diag}(1,1), L_{1}=\operatorname{diag}(20,20), L_{2}=\operatorname{diag}(50,50)$, $\gamma=1, \lambda_{1}=1, \lambda_{2}=1$.

The simulation results are shown in Figures 1-4. We can easily see that the robustness of FT-TDE is stronger than FIDC, and the response of FT-TDE is faster than FIDC. The response time is less than $0.3 \mathrm{~s}$, and both of the control inputs are nearly smooth and equivalent. 


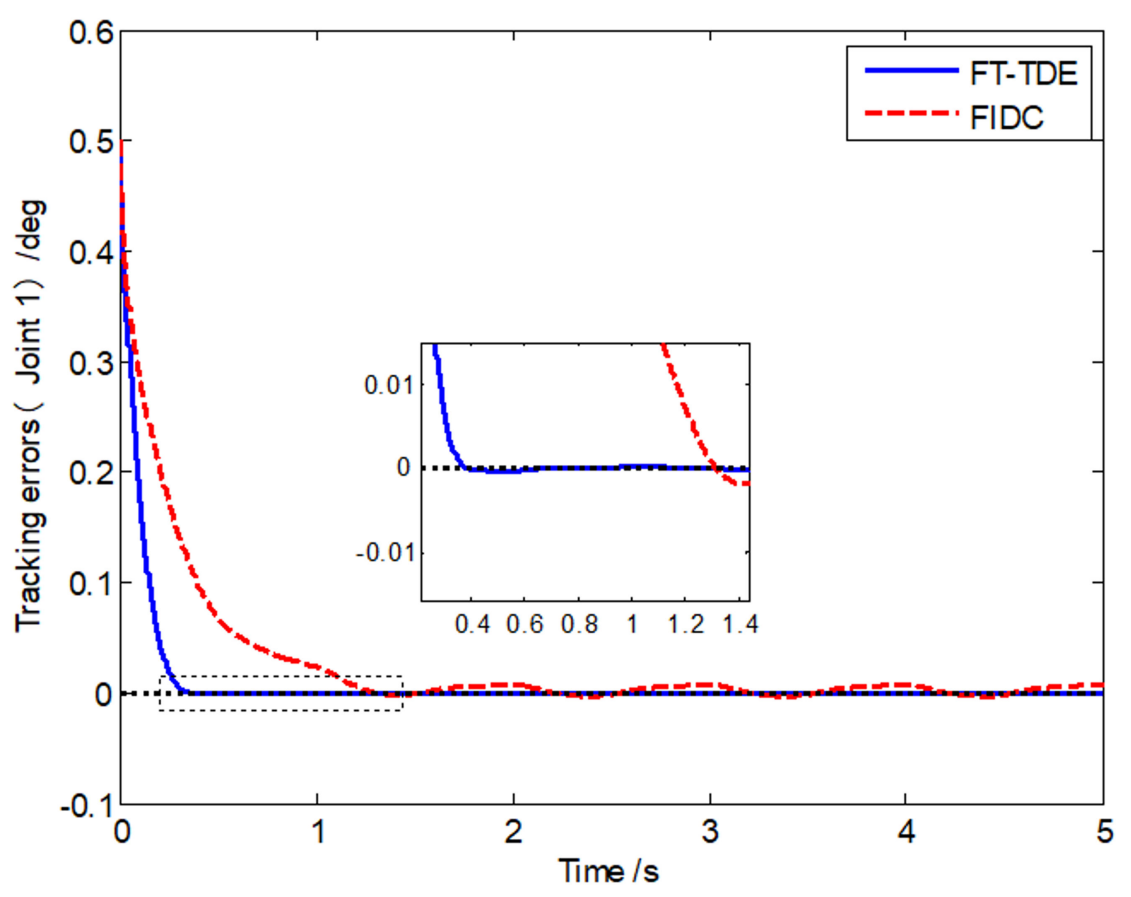

Figure 1. Tracking errors of Joint 1.

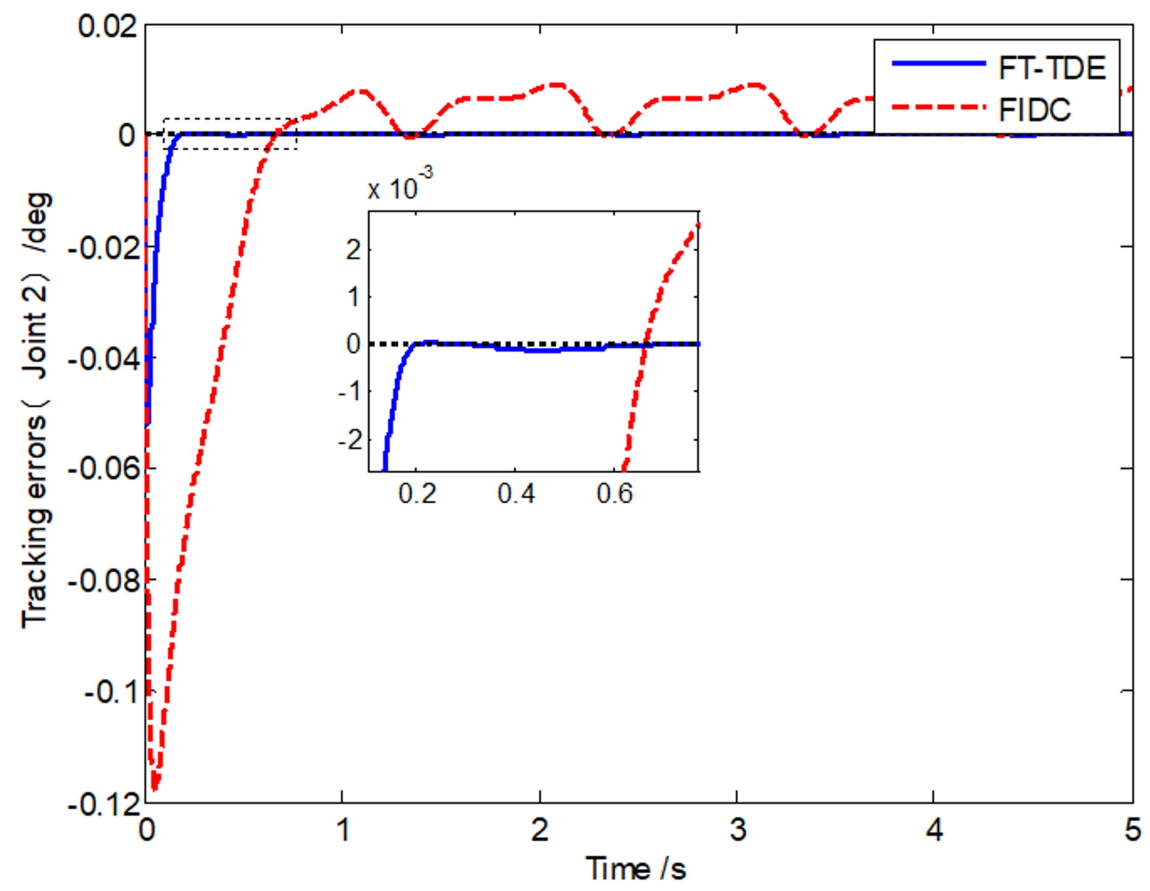

Figure 2. Tracking errors of Joint 2. 


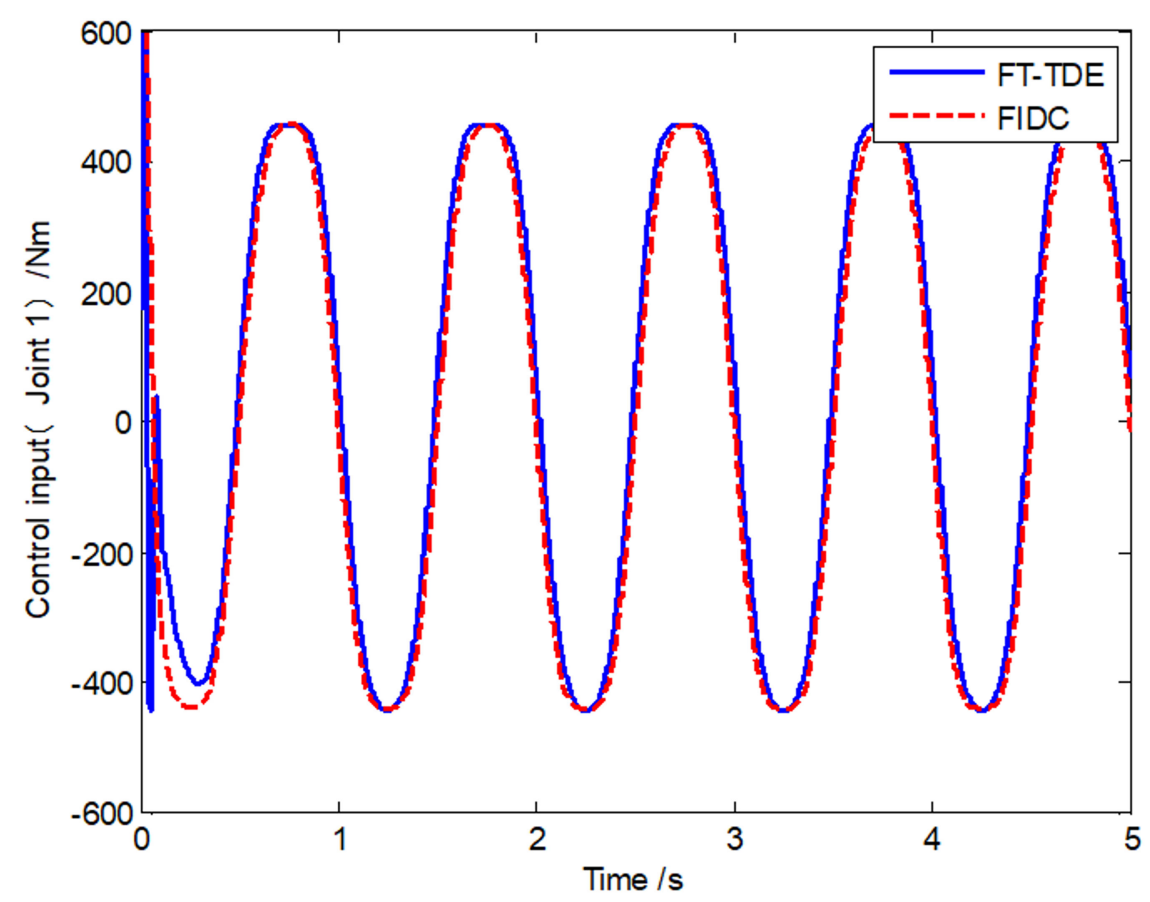

Figure 3. Control input of Joint 1.

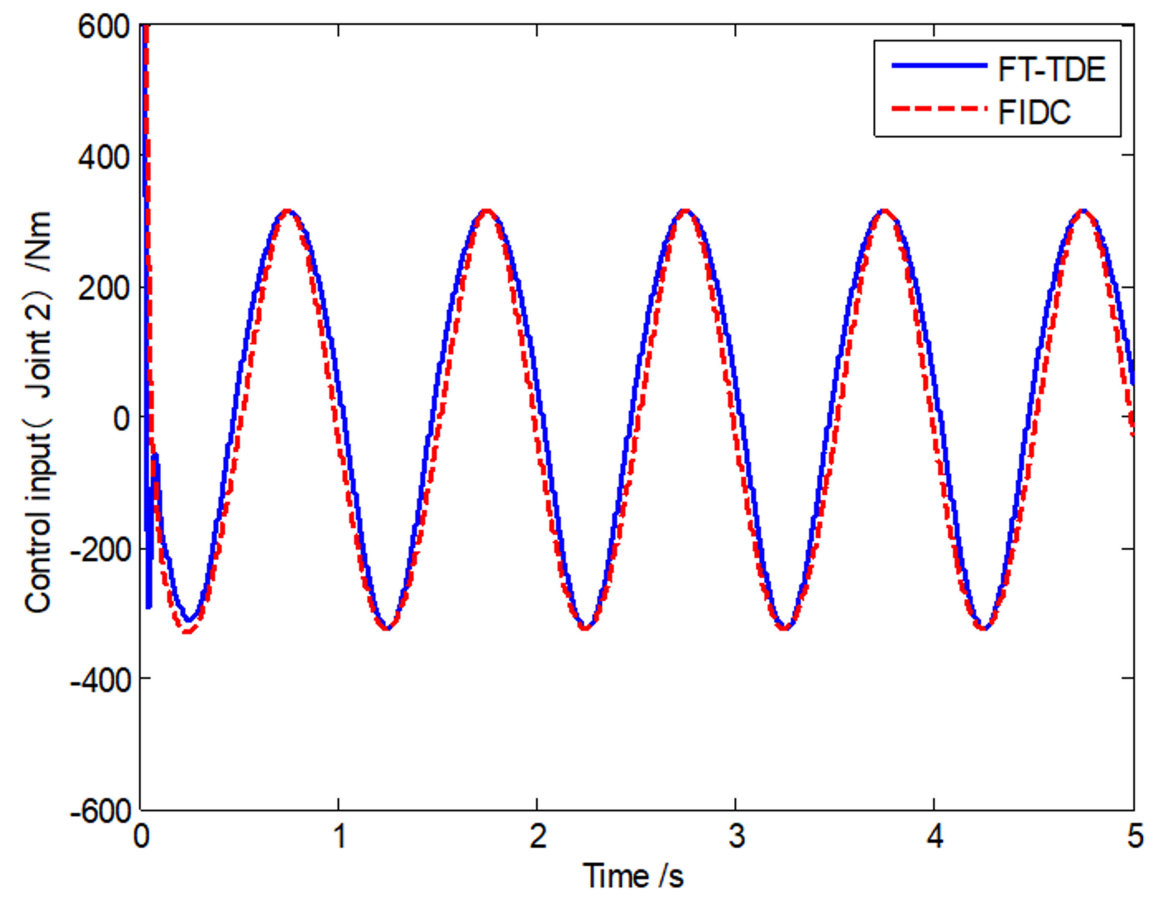

Figure 4. Control input of Joint 2.

(2) Robust finite-time output feedback control (FT-TDE-OB)

The observer parameters are set as $h_{1}=1, h_{2}=1, \varepsilon=0.001$. The simulation results are shown in Figures 5-8. From Figures 5-8, we can see that "FT-TDE-OB" is faster than "FIDC", but the tracking errors are more than other controllers, which is made by the high-gain observer. In practice, the observer parameters are required to be appropriately chosen, but the high-gain observer is very simple, and acts as a low pass filter. 


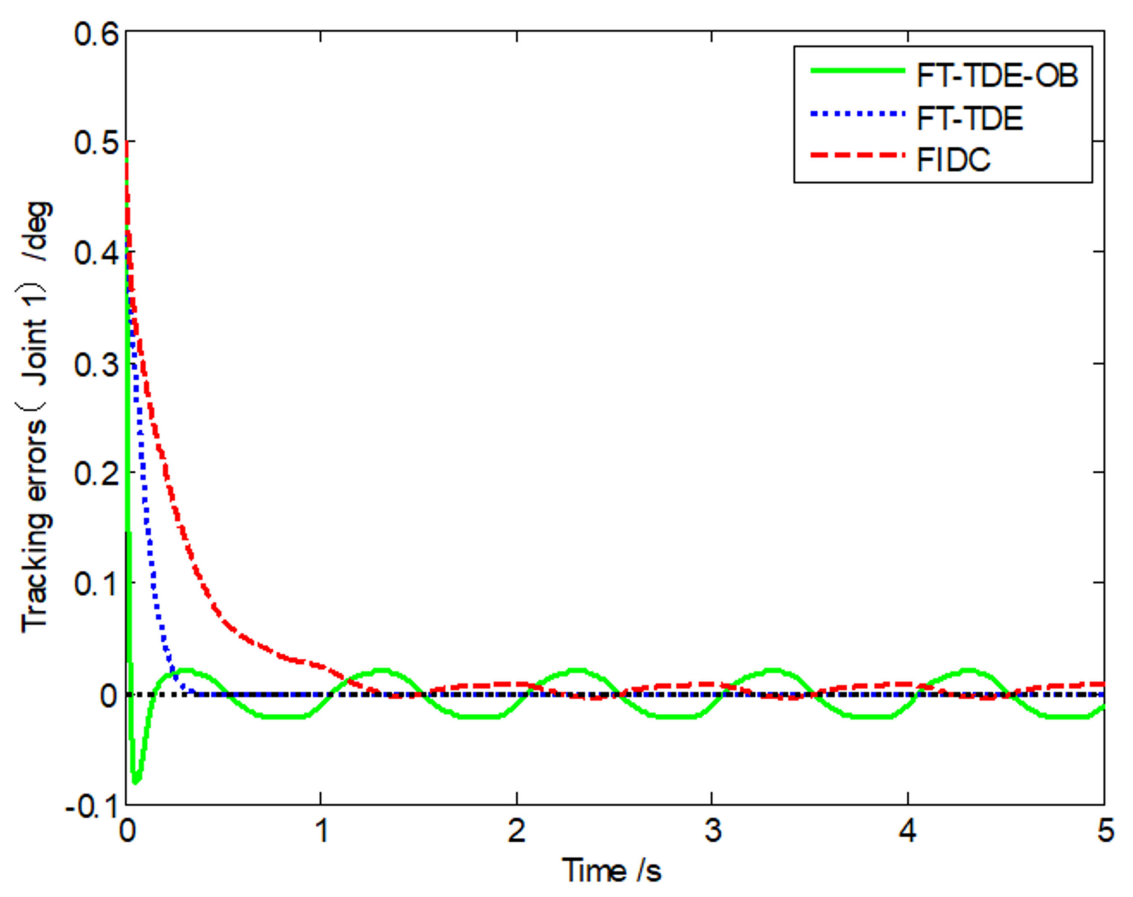

Figure 5. Tracking errors of Joint 1.

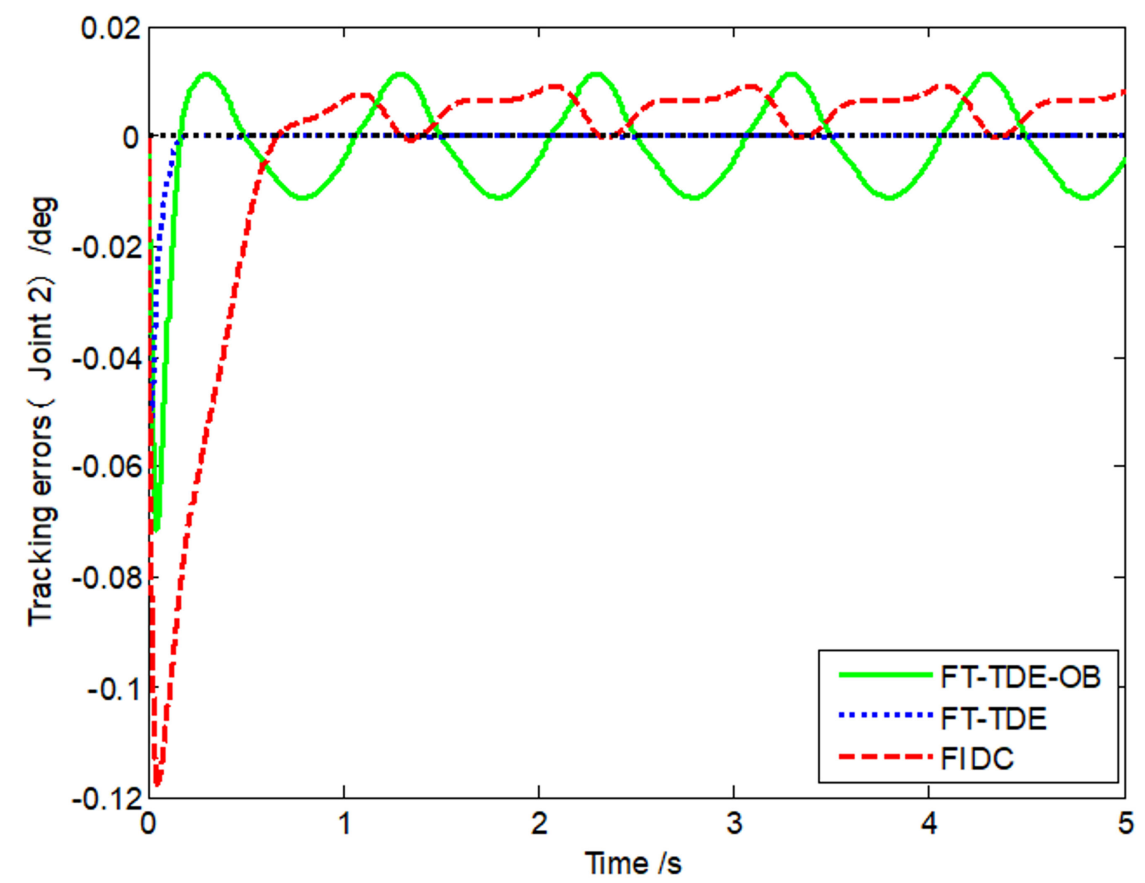

Figure 6. Tracking errors of Joint 2. 


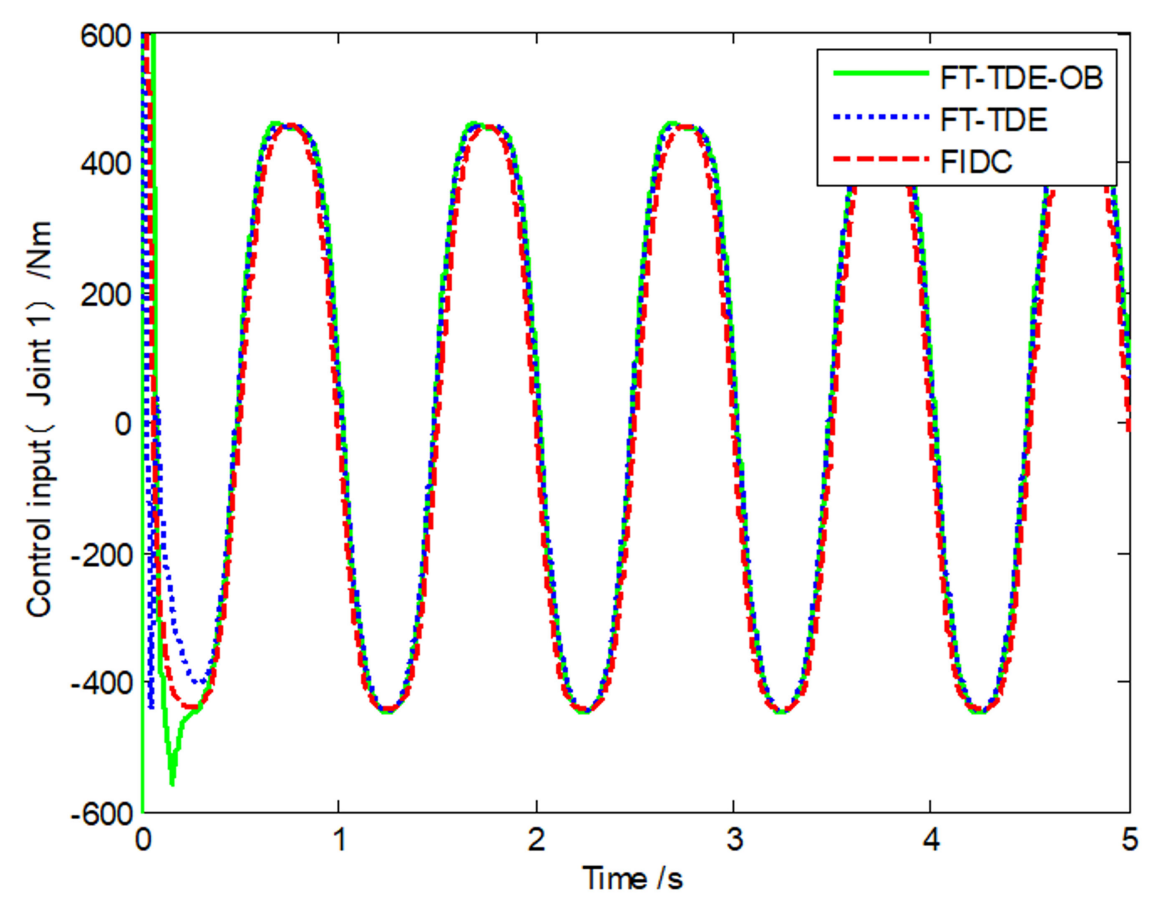

Figure 7. Control input of Joint 1.

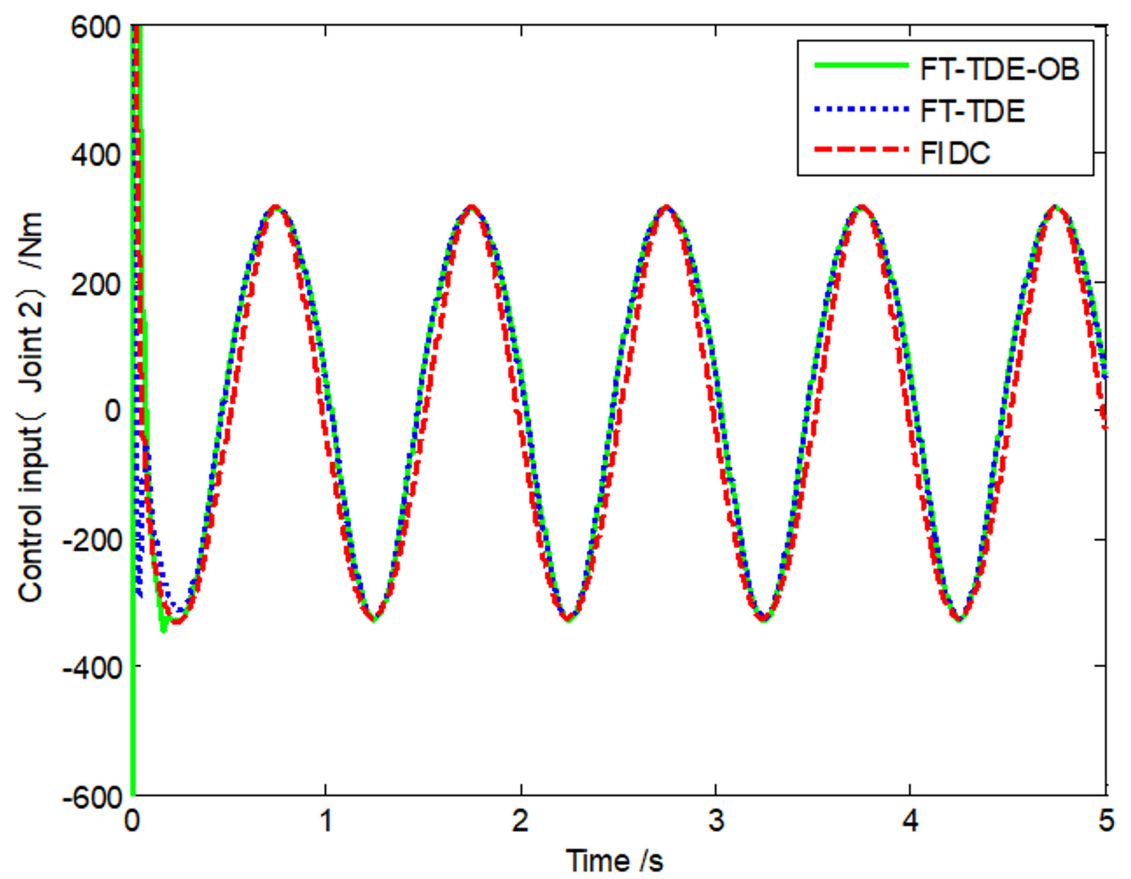

Figure 8. Control input of Joint 2.

\section{Conclusions}

In this paper, the time-delay estimation is used to simplify the robot dynamic model, so that the controller is very simple, and has an $L_{2}$-gain, which presents stronger robustness. The high-gain observer is employed to estimate the velocities, which lowers the device cost because there is no speed sensor needed. Simulations demonstrate the effectiveness of the proposed controller; the next work will be that the experiments research on the trajectory tracking control for robotic manipulators, which will be done to assess the control performances, including experiment design, algorithm optimization, performance testing, etc. 
Author Contributions: Writing—original draft, T.Z.; Writing—review \& editing, A.Z. All authors have read and agreed to the published version of the manuscript.

Funding: This work was supported by the Major National Science and Technology Projects (2015ZX04005006).

Conflicts of Interest: The authors declare no conflict of interest.

\section{Appendix A}

Boundness of TDE error [27].

Defining $u_{t}=\ddot{q}_{d}+v$, substituting the controller (6) into the Equation (2), we can obtain

$$
\delta_{t}=\ddot{q}_{t}-u_{t}
$$

and give

$$
\begin{aligned}
& M_{t} \delta_{t}=M_{t}\left(\ddot{q}_{t}-u_{t}\right) \\
& =\bar{M} u_{t}-F_{t}+\hat{H}_{t}-M_{t} u_{t} \\
& =\left[\bar{M}-M_{t}\right] u_{t}+\left[M_{t-L}-\bar{M}\right] \ddot{q}_{t-L}+\Delta F
\end{aligned}
$$

where $\Delta F=\hat{F}_{t}-F_{t}$ with $F_{t}=\Delta C(q, \dot{q}) \dot{q}+\Delta G(q)-\tau_{d}$ and $\hat{F}_{t}=F_{t-L}$. Obviously, $\Delta F=F_{t-L}-F_{t}$ is bounded for a sufficiently small $L$.

According to (5), the following equation holds:

$$
\ddot{q}_{t-L}=\delta_{t-L}+u_{t-L}
$$

Then

$$
\delta_{t}=E \delta_{t-L}+E \varsigma_{1}+\varsigma_{2}
$$

where

$$
\begin{gathered}
E=I-M_{t}^{-1} \bar{M} \\
\varsigma_{1}=u_{t-L}-u_{t} \\
\varsigma_{2}=M_{t}^{-1}\left[\left(M_{t-L}-M_{t}\right) \ddot{q}_{t-L}+\Delta F\right]
\end{gathered}
$$

By select an appropriate $\bar{M}$, the following equation can hold

$$
\|E\|=\left\|I-M^{-1} \bar{M}\right\|<1
$$

Clearly, $\varsigma_{1}$ and $\varsigma_{2}$ are also bounded for a sufficiently small $L$. Therefore, $\delta_{t}$ is bounded.

\section{References}

1. Wang, H. Adaptive Control of Robot Manipulators With Uncertain Kinematics and Dynamics. IEEE Trans. Autom. Control 2017, 62, 948-954. [CrossRef]

2. Guangjun, L.; Goldenberg, A.A. Robust control of robot manipulators based on dynamics decomposition. IEEE Trans. Robot. Autom. 1997, 13, 783-789. [CrossRef]

3. Shi, J.; Liu, H.; Bajcinca, N. Robust control of robotic manipulators based on integral sliding mode. Int. J. Control 2008, 81, 1537-1548. [CrossRef]

4. Haimo, V.T. Finite Time Controllers. SIAM J. Control. Optim. 1986, 24, 760-770. [CrossRef]

5. Bhat, S.P.; Bernstein, D.S. Finite-time stability of homogeneous systems. In Proceedings of the American Control Conference, Albuquerque, NM, USA, 4-6 June 1997; pp. 2513-2514.

6. Hong, Y.G. Finite-time stabilization and stabilizability of a class of controllable systems. Syst. Control Lett. 2002, 46, 231-236. [CrossRef]

7. Huang, X.; Lin, W.; Yang, B. Global finite-time stabilization of a class of uncertain nonlinear systems. Automatica 2005, 41, 881-888. [CrossRef] 
8. Li, J.; Qian, C. Global finite-time stabilization by dynamic output feedback for a class of continuous nonlinear systems. IEEE Trans. Autom. Control 2006, 51, 879-884. [CrossRef]

9. Zhao, D.; Li, S.; Zhu, Q.; Gao, F. Robust finite-time control approach for robotic manipulators. IET Control Theory Appl. 2010, 4, 1-15. [CrossRef]

10. Su, Y. Global continuous finite-time tracking of robot manipulators. Int. J. Robust Nonlinear Control 2009, 19, 1871-1885. [CrossRef]

11. Tang, Y. Terminal sliding mode control for rigid robots. Automatica 1998, 34, 51-56. [CrossRef]

12. Wu, Y.; Yu, X.; Man, Z. Terminal sliding mode control design for uncertain dynamic systems. Syst. Control Lett. 1998, 34, 281-287. [CrossRef]

13. Tan, C.P.; Yu, X.; Man, Z. Terminal sliding mode observers for a class of nonlinear systems. Automatica 2010, 46, 1401-1404. [CrossRef]

14. Feng, Y.; Yu, X.; Man, Z. Non-singular terminal sliding mode control of rigid manipulators. Automatica 2002, 38, 2159-2167. [CrossRef]

15. Abooee, A.; Moravej Khorasani, M.; Haeri, M. Finite time control of robotic manipulators with position output feedback. Int. J. Robust Nonlinear Control 2017, 27, 2982-2999. [CrossRef]

16. Ba, D.X.; Yeom, H.; Bae, J. A direct robust nonsingular terminal sliding mode controller based on an adaptive time-delay estimator for servomotor rigid robots. Mechatronics 2019, 59, 82-94. [CrossRef]

17. Jing, C.; $\mathrm{Xu}, \mathrm{H}$.; Niu, $\mathrm{X}$. Adaptive sliding mode disturbance rejection control with prescribed performance for robotic manipulators. ISA Trans. 2019, 91, 41-51. [CrossRef]

18. Kali, Y.; Saad, M.; Benjelloun, K. Optimal super-twisting algorithm with time delay estimation for robot manipulators based on feedback linearization. Robot. Auton. Syst. 2018, 108, 87-99. [CrossRef]

19. Kali, Y.; Saad, M.; Benjelloun, K.; Khairallah, C. Super-twisting algorithm with time delay estimation for uncertain robot manipulators. Nonlinear Dynam 2018, 93, 557-569. [CrossRef]

20. Su, Y.; Zheng, C. Global finite-time inverse tracking control of robot manipulators. Robot. Comput. Integr. Manuf. 2011, 27, 550-557. [CrossRef]

21. Galicki, M. Finite-time control of robotic manipulators. Automatica 2015, 51, 49-54. [CrossRef]

22. Liu, H.; Tian, X.; Wang, G.; Zhang, T. Finite-Time $\mathrm{H}_{\infty}$ Control for High-Precision Tracking in Robotic Manipulators Using Backstepping Control. IEEE Trans. Ind. Electron. 2016, 63, 5501-5513. [CrossRef]

23. Lebret, G.; Liu, K.; Lewis, F.L. Dynamic analysis and control of a stewart platform manipulator. J. Robot. Syst. 1993, 10, 629-655. [CrossRef]

24. Youcef-Toumi, K.; Ito, O. A Time Delay Controller for Systems With Unknown Dynamics. J. Dyn. Syst. Meas. Control 1990, 112, 133-142. [CrossRef]

25. Khalil, H.K.; Praly, L. High-gain observers in nonlinear feedback control. Int. J. Robust Nonlinear Control 2014, 24, 993-1015. [CrossRef]

26. Ahrens, J.H.; Khalil, H.K. Output feedback control using high-gain observers in the presence of measurement noise. In Proceedings of the American Control Conference, Boston, MA, USA, 30 June-2 July 2004; Volume 4115, pp. 4114-4119.

27. Maolin, J.; Jinoh, L.; Pyung Hun, C.; Chintae, C. Practical Nonsingular Terminal Sliding-Mode Control of Robot Manipulators for High-Accuracy Tracking Control. IEEE Trans. Ind. Electron. 2009, 56, 3593-3601. [CrossRef]

(C) 2020 by the authors. Licensee MDPI, Basel, Switzerland. This article is an open access article distributed under the terms and conditions of the Creative Commons Attribution (CC BY) license (http://creativecommons.org/licenses/by/4.0/). 